\title{
The role of material culture in human time representation: Calendrical systems as extensions of mental time travel
}

\author{
Authors \\ Johan De Smedt (corresponding author) \\ Ghent University \\ Department of Philosophy and Ethics \\ Blandijnberg 2 \\ 9000 Gent \\ Belgium \\ Phone: +3292647917 \\ Fax: +3292644187 \\ Email: johan.desmedt@ugent.be \\ Helen De Cruz \\ Katholieke Universiteit Leuven \\ Centre for Logic and Analytic Philosophy \\ Kardinaal Mercierplein 2 \\ 3000 Leuven \\ Belgium
}

\begin{abstract}
Humans have cognitive mechanisms that allow them to keep track of time, represent past events and simulate the future, but these capacities have intrinsic constraints. Here, we explore the role of material culture as an extension of internal time representations through anthropological and archeological case studies, focusing on Upper Paleolithic material culture. We argue that calendars complement and extend internal time representations, because they enable humans to project past events into the future more accurately than is possible with episodic memory alone, making them one of the factors that significantly improved foraging success during the Upper Paleolithic. We discuss the implications of the epistemic use of material culture for our understanding of the causes of shifts in human behavior during the Upper Paleolithic.
\end{abstract}

Keywords: mental time travel; episodic thinking; calendars; epistemic artifacts; cognitive archeology

This is the final draft of a paper that appeared in Adaptive Behavior

The reference to this paper is: De Smedt, J. \& De Cruz, H. (2011). The role of material culture in human time representation. Calendrical systems as extensions of mental time travel. Adaptive Behavior, 19, 63-76. 


\section{Introduction}

Ever since Darwin, comparative psychologists have considered the problem of the apparent mental discontinuity between humans and other animals. Why are humans, more so than other animals, capable of advanced cognition? Some authors have suggested that a distinctive feature of human cognition is its interaction with the external environment (e.g., Hutchins, 1995; Clark \& Chalmers, 1998). Humans rely heavily on environmental support such as books, electronically stored documents, nautical slide rulers, or simply pen and paper to delegate computational problems to the external world. How can we properly gauge the influence of artifacts in reasoning processes? Empirical investigations of the role of material culture in human cognition involve well-controlled conditions in which cognitive performance aided by external tools is pitted against purely internal mental operations. Kirsh and Maglio (1994), for example, compared the performance of subjects playing Tetris who were allowed to physically rotate blocks to fit them into the slots to players who were forced to mentally rotate them. The former performed faster and made less mistakes. However, participants in studies like these are typically Western college students, who are thoroughly enculturated into a world filled with artifacts that serve epistemic purposes, including banknotes, signposts, and nutritional information on packaging. It is no exaggeration to say that we inhabit a world that is primarily made up of our own creations, and many of these play a role in our cognitive lives. This makes it difficult to experimentally assess how unaided cognition (the naked brain) compares to externally aided cognition, or to examine the effects of material culture on human cognitive evolution. Some authors have developed computational models that examine how the use of the external environment can reduce cognitive load. Chandrasekharan and Stewart (2007), for example, have constructed a simulation where agents can learn to lower their cognitive load by generating taskspecific external cues, such as using their own tracks. In this paper, we will take a qualitative approach, concentrating on material culture used in epistemic contexts from extant small-scale societies with sparse material culture and prehistoric cultures, where people had not amassed such a vast body of epistemic artifacts (i.e., artifacts that help us think).

The aim of this paper is to develop an account of interactions between internal human cognitive abilities and external media based on findings from developmental and cognitive psychology, anthropology and cognitive archeology. We will argue that artifacts such as calendars extend evolved cognitive abilities by allowing humans to accurately predict cyclically occurring events. We use the term 'calendar' in a broad sense, as a shorthand for any artificial memory device that helps to recognize and record temporal events, such as astronomical or environmental observations. We take calendrical notation systems as a case study, because they do not physically alter the environment, but render it more cognitively congenial. They do not increase the number of potential prey in a territory; however, they enhance foraging success, amongst others by predicting animal migration events, and by allowing people to make preparations and arrangements in advance, thereby saving time and resources. As we will show, evolved human cognitive capacities that deal with time are limited in their ability to recognize cyclical events in the environment in a way that a coupled cognitive system, consisting of a calendar and interpreting humans, is not.

The paper begins with an examination of cognitive mechanisms for keeping track of time that are naturally available to humans, focusing on mental time travel. Cognitive psychological evidence indicates that mental time travel is a highly constructive process that is liable to distortion. As a result, the naked human brain cannot accurately predict 
cyclical occurrences such as animal migration events or the fruiting of plants. Next, anthropological examples will illustrate how humans routinely supplement their evolved mechanisms for keeping track of time with material objects (both natural events and especially designed epistemic artifacts). We then argue that the extension of mental time travel by material culture dates back to the late Middle Stone Age in Africa and the Upper Paleolithic in Europe, and illustrate this with examples of material culture interpreted by archeologists as calendars. We show that the emergence of the earliest unequivocal epistemic artifacts in the archeological record coincides with marked improvements in foraging efficiency. We conclude by briefly outlining possible ways in which the claims put forward in this paper could be tested using analytic and computational modeling.

\section{Cognitive processes underlying the perception of time}

\subsection{Salient systems of time processing}

The natural world is filled with temporal regularities, which organisms are adapted to exploit. Timing enables animals to anticipate opportunities and risks, which greatly improves their chances of survival. Multicellular organisms are equipped with circadian rhythms, internally generated 24-hour cycles. For shorter durations ranging from a few seconds to a few hours, animals rely on interval timing, which enables them to optimize their foraging behavior in terms of time and energy costs (Bateson, 2003). Some species possess highly specialized abilities to keep track of somewhat longer spans of time. Male house mice kill any neonate in their territory, except when they have mated 18 to 22 days before. During this period, when the possibility exists that the neonate is their offspring, they switch to nurturing behavior. This hormonal mechanism enables house mice to detect relationships between events widely distributed in space and time (fertilization and birth) that could never be perceived through associative learning alone (Kummer, 1995).

The Earth's yearly orbit around the Sun produces seasons, cyclical climatic changes that have a high impact on animal fitness. Seasonal fluctuations in temperature, food availability and predation pressures pose challenges to survival and reproduction. Consequently, many species have acquired seasonal behavioral and physiological adaptations, such as migration, seasonal mating, hibernation and changes in pelage or plumage. In many cases, these adaptive responses are directly triggered by environmental fluctuations. Nevertheless, as many shifts in behavior would occur too late if they were a direct response to environmental factors, there is intense selective pressure on the capacity to anticipate seasonal changes - if squirrels waited to store nuts until the onset of winter, their caches would be insufficient to help them through winter.

Some animal species can anticipate future events that are highly variable and hard to predict from external cues alone, using past experience as a proxy for the future. Western scrub jays (Aphelocoma californica) cache both perishable (e.g., larvae) and non-perishable (e.g., seeds) foodstuffs. Under experimental conditions, their recovery of previously stored items shows sensitivity not only to what type of food was cached but also where and when it was stored, enabling them to prioritize perishable items (Clayton \& Dickinson, 1998). Moreover, these corvids also appear to be able to anticipate the future: they flexibly adapt their caching behavior to future needs, such as preferentially caching food in a room where they foresee they will be hungry the next day (Raby, Alexis, Dickinson, \& Clayton, 2007). This ability to take into account future events independent of current motivations is rare in the animal world, and can plausibly be explained as the result of selective pressures that are associated with food caching. A comparative study (Stevens, Rosati, Ross, \& Hauser, 2005) with two types of New World 
monkeys indicates that feeding ecology indeed exerts considerable selective pressures on an animal's ability to take into account future events. Marmosets (Callithrix jacchus), which feed on tree exudates, require patience to wait for sap to exude from the trees, whereas tamarins (Saguinus oedipus), whose diet is composed mainly of insects, perform more quick, impulsive actions. As a consequence, marmosets are willing to wait much longer than tamarins to obtain a larger food reward. One can glean from these examples that ecological conditions and feeding behavior are important factors in shaping cognitive processing of time.

\subsection{Episodic thinking and mental time travel}

Since current and historical human populations, including hunter-gatherers, horticulturalists, fishers and farmers, rely on food that is seasonally variable, we can expect that Homo sapiens has cognitive adaptations that allow for the recognition of temporal regularities of the environment. Humans are equipped with circadian rhythms and interval timing. Next to this, they rely on past experience to simulate future events. This ability is termed episodic thinking or mental time travel. Episodic memory (see Tulving, 2002, for review) refers to our capacity to remember personally experienced events and to mentally travel back in time to re-experience those events; it is distinct from semantic memory, which stores factual knowledge about the world. The ability to travel mentally into our experienced past is supplemented by episodic future thinking (Atance \& O'Neill, 2001), a capacity to project oneself into the future to simulate possible scenarios, enabling one to foresee possible future consequences of one's current behavior, or to make preparations in anticipation of a planned activity.

A growing body of empirical evidence indicates that episodic memory and episodic future thinking are subserved by the same neural mechanisms. Their onset during cognitive development is synchronous. Episodic memory arises gradually between three to five years of age (Perner \& Ruffman, 1995). Although younger children's rapidly expanding lexicon indicates that they have an excellent semantic memory, they seem unable to store long-term autobiographical memories. For example, when taught a novel fact (e.g., a new color name) or skill, three-year-olds believe that they have always possessed this knowledge; the realization that this is not the case only emerges between four and five years of age. The ability to travel mentally into the future follows a similar developmental trajectory (Thompson, Barresi, \& Moore, 1997): given the choice between a small immediate reward and a larger delayed reward, only children of four years and older forgo immediate gratification and choose the delayed one.

More direct evidence that episodic memory and episodic future thinking are subserved by the same neural circuits comes from neuropsychology. An fMRI study by Addis, Wong and Schacter (2007) found that imagining future experiences or recollecting vivid memories activates a similar network of brain regions, including the left hippocampus and posterior visuospatial regions like the right middle occipital gyrus. Hassabis, Kumaran, Vann, and Maguire (2007) examined the ability of amnesic patients with focal hippocampal damage to imagine fictitious autobiographical experiences, such as visiting a museum or sunbathing on a tropical beach. Their subjects showed a seriously compromised ability to make vivid, detailed and sensory descriptions of imagined experiences. Presumably, episodic memory and episodic future thinking are subserved by the same neural correlates because they share similarities in terms of their underlying psychological mechanisms. Both are constructive processes, which require a system that flexibly recombines bits and pieces of information from various sources. Therefore, we shall refer to episodic memory and episodic future thinking collectively as 'mental time travel', following Suddendorf and Corballis (1997). The likely adaptive 
function of mental time travel is not to recollect past events per se, but to enable one to anticipate and predict future events on the basis of past experiences. According to Suddendorf, Addis and Corballis (2009, p. 1319), episodic memories provide a vocabulary from which one can construct possible scenarios, which can be compared in order to optimize future behavior. Its combinatorial flexibility allows one to predict the consequences of events that one has never experienced, leading to the prediction that pickled herring with chocolate is a challenging combination of tastes, or that a naked dance in front of one's superior will get one fired, unless one is a professional pole dancer.

\subsection{Mental time travel as a human cognitive specialization?}

Since Suddendorf and Corballis (1997) suggested that the ability to travel mentally in time is a uniquely human cognitive specialization, comparative psychologists have developed experimental paradigms to investigate this capacity in nonhuman animals. To date, the strongest candidate is the Western scrub jay: as mentioned earlier, members of this species appear to remember where and when they previously cached food-items. However, their mental time travel seems to be highly domain-specific, only concerned with the caching and retrieval of food, whereas human mental time travel is domaingeneral: we are able to reminiscence or anticipate upon virtually any aspect of our personal lives, be it food, social encounters, or weather circumstances (Suddendorf et al. 2009). Nevertheless, the accuracy of some nonhuman animals is superior to that of humans - whereas scrub jays can cache food based on future needs irrespective of current utility, humans exhibit systematic errors in predicting the consequences of their actions. The latter are driven by current feelings of hunger or satiation to predict future appetite: hungry subjects are more likely than satiated participants to choose a high calorie snack to eat at a distant point in the future, and hungry people mistakenly expect to like eating spaghetti for breakfast the next day (Gilbert, Gill, \& Wilson, 2002). If there is indeed a qualitative difference between mental time travel in humans and memory in some nonhuman species, it remains unclear what this difference might be. As we will argue, an underexplored possible explanation is that humans, unlike other animals, routinely supplement their episodic thinking with material culture.

Given that episodic memory and future thinking are constructive processes, it is not surprising that they are liable to distortion. Mental time travel involves the simulation of future experiences through past events, leading to the omission of inessential features, the abbreviation of the simulated event (which is, of course, less long than the true event), and the absence of context. Indeed, episodic memory retains only information that is likely to be needed for future reference-we rarely need to remember all the exact details of our experiences. For example, people typically remember their worst trainmissing experience when simulating how painful and inconvenient a next train-missing experience will be (Morewedge, Gilbert, \& Wilson, 2005). These puzzling features of episodic recall can be explained by the hypothesis that mental time travel does not serve the adaptive function of a disinterested representation of true events, but that it allows for simulations that guide action in adaptive ways. Overestimating the discomfort of an unpleasant experience may help us avoid that situation in the future. Adaptive as this may be, it poses severe limitations on the reliability of our long-term episodic memories.

Numerous experiments (e.g., Marsh \& Tversky, 2004) show that even vivid and confident episodic memories are vulnerable to distortion. Retelling personal recollections typically involves exaggerations, omissions, and simplifications to entertain or help the audience better understand. Under controlled experimental conditions, biased retellings of events alter the memories one has of these events (Tversky \& Marsh, 2000); they 
routinely become part of one's own episodic recall, replacing more accurate memories. People can also be induced to remember personal experiences that have never happened. In a series of experiments, Loftus and co-workers gave participants descriptions of childhood experiences provided by family members, and encouraged them to remember these (see Loftus, 2003, for an overview). One of these stories was actually a pseudoevent that had never taken place (e.g., getting lost in a shopping mall at age five and eventually being rescued by an elderly person). About $25 \%$ of participants claimed to "remember" this traumatic childhood experience, often adding embellishing details to their accounts. As Loftus (2003, p. 872) puts it "the story creates a memory rather than the other way around." Precisely because narratives require subjects to generate their own details, they encourage false memories. Memory distortion can thus be seen as part of the adaptive operation of a healthy memory system.

\section{Material culture and internal time representation}

Animals regularly modify their external environment in order to reduce the number and cost of mental operations. For example, ants mark paths from food-sources to the nest with pheromone trails, because it is easier to follow a pheromone trail than to store and compare landmarks, which places high demands on visual memory. Kirsh (1996) terms such actions epistemic actions, because they are not aimed at bringing about physical goal-directed changes in the environment, but rather at making it more cognitively congenial. Drawing a map, for instance, does not physically alter the environment, but makes it easier to navigate - one does not have to level the terrain or cut trees to get a comprehensive overview. Humans rely on external cognitive resources to a considerable extent - they fashion tools that are explicitly aimed at fulfilling epistemic needs. One need but think of instruments, such as compasses or thermometers, which allow for accurate measurements, external memory storage in texts or diagrams, or objects that otherwise lighten cognitive load, like tallies or calculators. Such epistemic artifactswhich are made to serve epistemic purposes - are a distinctive feature of human cognition. Nonhuman animals sometimes use objects for epistemic purposes, such as the female gorilla observed by Breuer, Ndoundou-Hockembal, and Fishlock (2005) that probed the depth of a pool with a stick before deciding to cross it. To our knowledge, however, no animal has ever been observed to make tools (i.e., intentionally modify objects) primarily for epistemic purposes.

The use of external media is not limited to contemporary societies, but seems to be a pervasive element of human cognition at least since the Late Pleistocene (ca. 120,000 years ago). From this period onward, archeologists find shell beads, notched

pieces of ochre and bone, and - somewhat later-representational art, demonstrating that humans conveyed ideas externally in symbolic media. Some authors have proposed to incorporate this extended cognition as a key element in human cognitive evolution. For example, the cognitive archeologist Mithen (2000) argues that the emergence of modern human behavior during the past 100,000 years was not so much due to intrinsic changes in brain organization as to the emergence of cultural practices that incorporate artifacts into reasoning processes, like the use of representational art as memory storage devices. The cave paintings of Lascaux (Dordogne, France, about 18,600 BP), for instance, can be seen as mnemonic devices that display animals with their feet turned toward the spectator, which allowed the artists to depict the shape of the hoof prints of particular prey species, such as bison and horse (Mithen, 1988). In this way, future hunters could learn the connection between spoor and prey. To Mithen (2000, p. 214), artifacts are especially suitable to represent ideas that have "no natural home within the mind," such 
as religious beings. Since religious agents are not obviously physically present, thinking about them is often structured by artifacts, like paintings, masks, or sculptures. In what follows, we examine how humans also rely on their external environment to complement their evolved capacity for mental time travel.

\subsection{Extending the mind to keep track of cyclical occurrences}

As we have seen, future events are rarely replicas of past ones - a constructive episodic memory, which retains a gist of what has happened is therefore more flexible than a hypothetical memory that would store rote records of the past. But this means that mental time travel falls short of accurately predicting long-term cyclical occurrences. Annual phases in the life cycle of animals and plants, such as spawning migrations of fish or the fruiting of trees occur reliably in the same seasons. Being able to predict these events would have dramatically improved foraging success in prehistoric hunter-gatherer communities. A clear example is Late Pleistocene Europe, where humans primarily relied on animal protein for their diet. Fatty meat is much higher in caloric content than lean meat, but wild mammals are lean most of the year and only store fat during specific phases in their life cycle. Reindeer, an important prehistoric food-source, store fat during the late summer and early autumn. During the rutting season (in the late fall), they quickly lose this fat and only regain it by next summer. Cave paintings in Lascaux, Niaux, and other Late Pleistocene Franco-Cantabrian sites indicate that hunter-gatherers were sensitive to these seasonal changes, as they frequently depict reindeer with exaggerated humps of fat (Delluc \& Delluc, 2006). Hunter-gatherers who tuned their migrations to coincide with those of the reindeer during early autumn could maximize their energy intake by hunting this prey species.

Moving away from high latitudes, the arid Australian inland, which was colonized by humans as early as 50,000 years ago (Roberts, Jones, \& Smith, 1990), provided dramatic challenges in terms of seasonal availability in food, water, shelter and artifactmaking materials. Rainfall is sparse and seasonal, and the onset of seasons is highly variable. As a result, Australian nonhuman vertebrates have developed a wide variety of adaptive responses. For example, the freshwater turtle Chelodina rugosa lays eggs in low-lying areas during the wet season. The embryo only begins to develop once the egg is exposed to the air which permits a synchronization of the organism with external conditions (Shine \& Brown, 2008). Humans do not have such specialized physiological adaptations to variable events; their internal memory likewise seems insufficient to allow storing fine-grained details like co-occurrences of subtle seasonal changes with phases in animal life cycles. Humans equipped with nothing but their naked brains are thus unable to reliably predict such cyclical occurrences. Since distorted retellings corrode episodic memories, and narratives can induce false memories, sharing reminiscences with a wider audience does not increase their dependability. Caspari and Lee (2004) have explained the Upper Paleolithic symbolic revolution mainly as a consequence of increased human longevity. They argue that intensified oral intergenerational transmission of complex cultural information may have contributed to the innovations associated with behavioral modernity. Some computational models (e.g., Powell et al., 2009) indeed indicate that increases in communication improve the transmission of skills. However, as we have seen, experimental psychological evidence strongly suggests that episodic memories are susceptible to distortion through retelling, leading to the prediction that distributing cognition through oral communication alone may be insufficient to transmit some forms of complex cultural information. Especially if information is transmitted over many generations, it may get distorted through retelling, or may simply be lost through gaps in 
the transmission process. Thus, we can expect that the use of epistemic artifacts markedly improved the conceptual stability of transmitted representations.

Anthropological investigations of recall in non-literate societies provide evidence for this crucial role of externally stored information. Australian aboriginals use multiple strategies to remember and transmit knowledge of the local geography, such as the presence of water-sources, which are crucial for their survival. They associate oral narratives with particular places in the landscape, the so-called Dreaming - their natural environment thus becomes an epistemic aid. Crucially, several of these stories are recorded as dot paintings on bark (Sharifian, 2003). Next to this, many aboriginal groups associate the ripening of particular fruits or occurrences of specific animals with the arrival of particular constellations. For example, in Arnhem Land, the harvesting of reeds to make fish-traps commences when Arcturus is seen in the eastern sky at sunrise (Clarke, 2009). In stark contrast, the memory of aboriginal forebears is notably shallow: people tend to remember ancestors only as far back as their grandparents. An important reason for this brief recall is that information about persons is not stored materially, but only orally recounted. During retellings, this information is habitually edited and reformulated to match the fluid social relationships between different families within these small-scale communities (Sansom, 2006). By contrast, in nonliterate cultures where genealogical recall is vital for the local political and social order, material culture serves to store genealogical knowledge. The Luba from Congo use flat wooden boards studded with pins and beads to teach neophytes about historical events, such as migrations and royal genealogies. The shape, colors and spatial configurations of the pins and beads help them to accurately remember and transmit these events. Interestingly, many of the elements presented in their oral history are also found in the archeological record of Luba kingdoms, which stretches back to more than 1500 years (Nooter Roberts \& Roberts, 1996).

\subsection{Material anchors and epistemic artifacts}

In disparate cultures, people keep track of cyclical events by extending their evolved internal timing mechanisms into the world, i.e., they use cyclical natural events as material anchors. Obvious candidates are the phases of the moon. They are easy to observe, but synodic (phase cycle) lunar years are about 11 days shorter than solar years, which would soon lead to an accumulation of errors rendering lunar calendars useless for the purpose of tracking seasons. The epistemic role of material anchors is aptly illustrated by the Borana lunar calendar and its calibration to prominent star clusters (Bassi, 1988). The Borana from northern Kenya and southern Ethiopia use synodic lunar months to construct their calendar. This calendar is of vital importance to their subsistence and ceremonial activities, and is regulated by ayantu, experts on sky observation. To calibrate it, the ayantu add an intercalary month approximately every three years. Their decision to add an extra month is solely based on astronomical observations, namely when the moon rises in conjunction with a particular succession of reference stars on successive nights. Borana astronomers make multiple night sky observations, formulating hypotheses about the future behavior of celestial bodies and testing them on observations the following nights. The star clusters play an important epistemic role, as they are the sole guides in the ayantu's decision to add the extra month. By using astronomical observations, the Borana can oversee a period spanning three years, which would otherwise be impossible within this nonliterate society. Horticulturalists from the Torres Islands of Vanuatu (Melanesia) traditionally calibrate their lunar calendar to seasonal events. The appearance of a ubiquitous sea-worm, palolo, in October marks the planting of yam and other garden crops. The metamorphosis of a local species of ant into its winged phase, vühoro, in 
January serves as a marker for the end of the planting cycle (Mondragón, 2004). Material anchors need not be restricted to the visual modality. Aboriginal inhabitants of Queensland, Australia, know that when the black beans are ready to eat, it is time to hunt jungle fowls (Clarke, 2009). The Andaman Islanders knew a calendar of scents: the distinct succession of odors in the densely covered jungles was used to mark different periods of the year (Radcliffe-Brown, 1922). The Yanyuwa from the southern Gulf of Carpentaria, northern Australia, use a wind calendar to identify their five seasons: changes in intensity, humidity and direction of local winds are used to optimally time fishing, and gathering eggs, buds and nuts (Clarke, 2009). In all these cases, the timing of cyclic activities (such as hunting, weeding and harvesting) is rendered more optimal and reliable by tying it to cyclical occurrences in nature.

Next to natural material anchors, humans across the world draw on especially designed artifacts to keep track of cyclical events. Artifacts have the advantage that they are less constrained by processes in nature, thereby further enhancing the stability of the representation of cyclical events. The Mandan (a Native American Great Plains culture) recorded lunar phases as rows of crescents onto sheets of paper. Some of these are accompanied by plant symbols, indicating a record of planting and harvesting (Thornton, 2003). The stick-calendars in the shape of hexagonal prisms of the Yakut, a subarctic Siberian culture subsisting on hunting, gathering and herding reindeer, show two months along each edge, incised with day units (Marshack, 1991). Several days on the Yakut calendar bear signs to mark seasonal events (e.g., the flowering of certain plants), astronomical observations (e.g., the appearance of the Pleiades, important in their shamanic rituals), as well as Christian (Orthodox) holidays. In Chankillo, Peru, a megalithic calendar of 2,300 years old, consisting of 13 aligned towers, was calibrated to the winter and summer solstices. The towers and gaps in between enabled tracking the progress of the Sun to within an accuracy of two or three days (Ghezzi \& Ruggles, 2007), which was vital for agriculture in this arid region that lies in the rain shadow of the Andes.

\section{Evidence for the extended mind in the archeological record}

Artifacts like shell beads, notched bones and ochre plaques represent the earliest concrete evidence for storage of symbolic information outside of the human brain. Here, we discuss direct and indirect evidence that suggests that during the Late Pleistocene humans started to use material culture to store cyclical events externally, and that this was one of the factors that had a significant impact on human foraging success. As reviewed above, the human brain is not naturally equipped to recall cyclical events. Cross-cultural evidence from non-literate societies shows that people rely on material anchors to remember such events accurately. On the basis of this, we expect the appearance of artifacts that were used to keep track of time to coincide with improved foraging success. In what follows, we will discuss several material devices that were used by Pleistocene hunter-gatherers to keep track of time, focusing on incised bone and antler objects, and rock art. Next, we indicate changes in human behavior during the same period that suggest an improvement in foraging efficiency.

\subsection{Incised bone and antler objects}

Upper Paleolithic bone and antler objects with regular incisions have been recovered since the 1860s. The fact that they have ordered sets of notches or incisions indicates that these artifacts were used to represent numerical information. Marshack (1972) proposed the influential hypothesis that many of these objects were lunar calendars. His conclusion 
that notched bones represent the first human notation systems has gained general acceptance in the cognitive archeological community. However, he assumed that these notched artifacts always reflected a long term, cumulative, sequential notation, a view that is now called into question. Based on microscopic analysis, d'Errico (1998) developed a theoretical framework and an explicit methodology for evaluating the manufacturing process of incised bone objects. When morphologically resembling tools were used and abandoned subsequently, the accumulation of the engravings was probably gradual, similar to a tally-stick. If, in contrast, morphologically distinct burins (e.g., antler plaque from Abri Blanchard, see below) were used simultaneously, one can infer that the artifact was conceived as a whole, representing different items with different symbols, as is the case in a calendar. The code for the symbols is lost, as we do not have enough information about these prehistoric societies to find out what they meant. However, from ethnographic parallels we can infer plausible functions of these objects.

One of the oldest probable lunar calendars is an antler plaque from Abri Blanchard, France, dated to about 32,000 BP. This object was more than a simple tally (counting a number of past nights); it was made with the intention of being a timekeeping device: a recent detailed formal analysis of the artifact (Jègues-Wolkiewiez, 2005) reveals that its maker prepared the surface carefully with a set of notches at the edges, forming a rough coordinate system, to plot his or her inscriptions. One of its sides is engraved with some 70 morphologically differentiated cavities that resemble successive phases of the Moon, the serpentine trajectory of the notches reflecting the actual position of the spring Moon in the sky in the Dordogne region upon setting. In this way, the Abri Blanchard plaque is a hybrid representation, depicting both the phases of the Moon and its position in the sky (Fig. 1): the differently shaped notches indicate phases of the moon, as well as its position. The dates (based on current astronomical observations in the region) are those corresponding to the current position of the moon. Four cavities to the left and two cavities to the right of the serpentine are separated from the other cavities by fine lines. Jègues-Wolkiewiez (2005, p. 57-58) speculates that these are probably mistakes that have been noticed by the engraver, hence separated from the main drawing.

Fig. 1: Antler plaque from Abri Blanchard. Note the notched edges, which provide the coordinate system. (Drawing based on Figs. 1, 3 and 13 from Jègues-Wolkiewiez, 2005.)

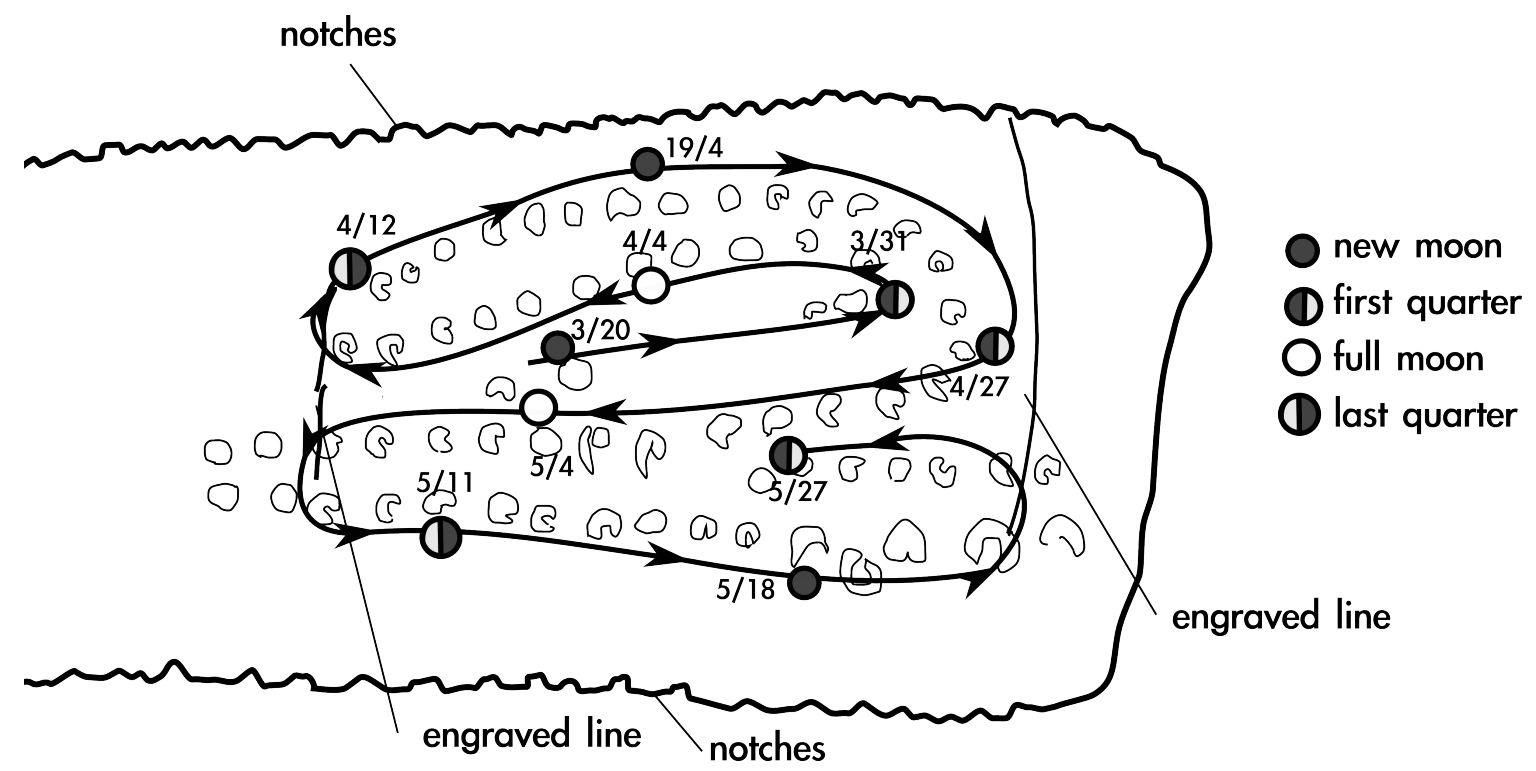


Some Paleolithic notched artifacts show pictorial images, which may hint at the meanings associated with the notations. The antler baton from Cueto de la Mina (Fig. 2), Spain, dated to the Late Magdalenian (about 12,000 BP) presents several sets of notches, which are made with different angles, pressures and directions, suggesting a code based on morphological differentiation. Each of these sets is accompanied with a different image: two schematic ibex or chamois heads and at least four kinds of plants in different stages of growth (Marshack, 1972). Many hunter-gatherer cultures use plants to predict seasonal changes in rainfall and temperature (see e.g., Clarke, 2009, for a discussion of plant-based calendars in Australian aboriginal societies). Pleistocene hunter-gatherers may also have used plants in this way, recording their different stages of growth as a means of time keeping (see 1-4 and 7 on Fig. 2). Like in the Mandan and Yakut calendars, these icons were probably used to mark seasonal events. Interestingly, archeological analysis of the site (Baxter, 2001) suggests that Cueto de la Mina was an aggregation locale, a place where hunter-gatherer groups annually came together to exchange food, sexual partners and technological skills - the temporal animal and vegetative clues (when did these animals migrate, when were these plants in these particular stages of growth) on this antler piece may have facilitated this.

Fig. 2: Antler baton from Cueto de la Mina. It has several sets of notches that are associated with images of plants $(1-4,7)$ and two animal heads, probably ibexes or chamois $(5,6)$. Redrawn from Marshack (1972), p. 456, Fig. 15.

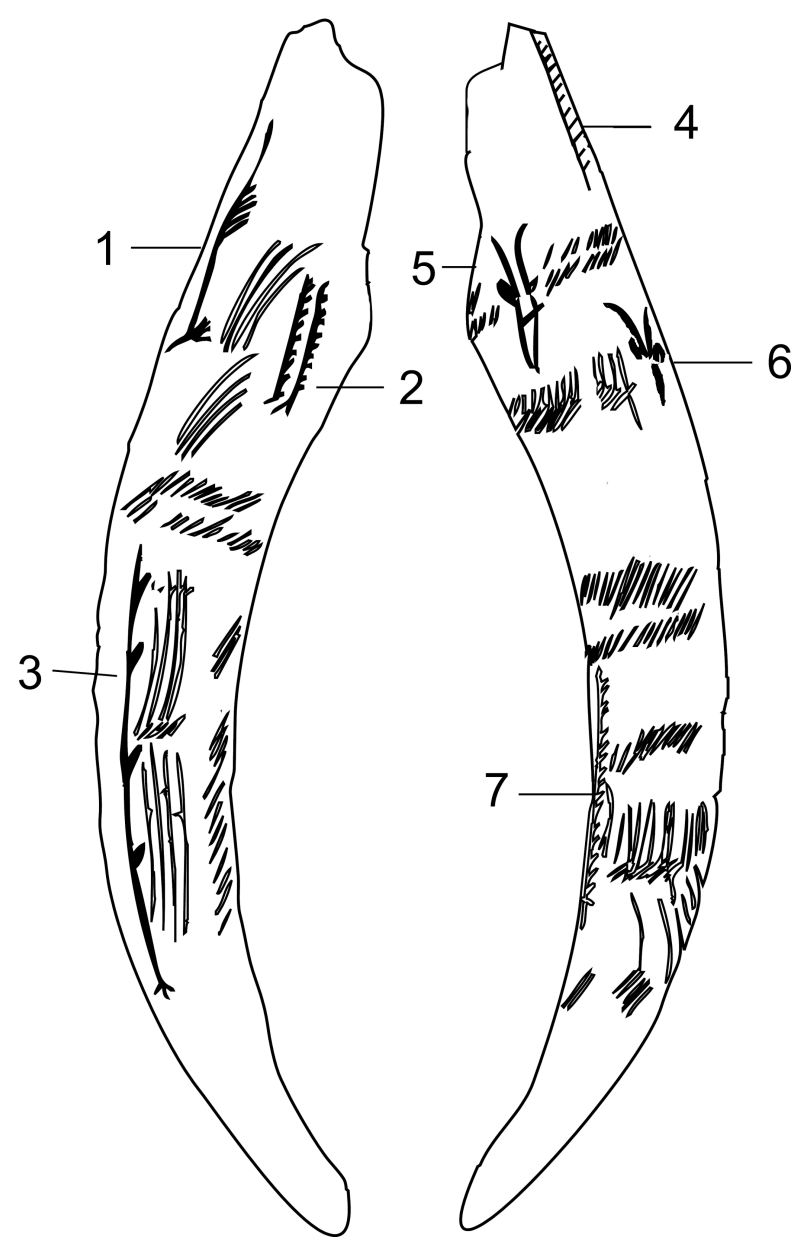




\subsection{Rock art}

Next to incised bone and antler objects, Paleolithic rock art also served as artificial memory system for storing ecologically relevant information about seasons. Rock art often emphasizes information useful to hunters, such as the exaggerated representation of fat deposits on horses and aurochs, or the depiction of footprints of prey species in lieu of hooves (Mithen, 1988). As a detailed analysis by Delluc and Delluc (2006) shows, rock art from well-known Franco-Cantabrian sites like Chauvet, Lascaux and Niaux is rich in seasonal information. Lascaux and Niaux (French Pyrenees, about 12,890 BP) have depictions of horses in different seasons. Horses in summer dress are heavy, with short, light fur, whereas those in winter pelage are typically leaner, with a longer tail and manes, and darker, scruffier fur. Most large herbivores are pictured in their specific winter or summer appearances; for instance, reindeer are shown in summer dress, with large antlers and fat deposits. Additionally, some rock paintings in Lascaux show mating behavior that is restricted to early spring, such as two bison bulls intimidating each other and a stallion closely following a mare. We are not claiming that these paintings were used as calendars; rather, we argue that one of their functions was probably mnemonic, by visually representing what prey species look like in specific seasons.

Next to large terrestrial herbivores, Upper Paleolithic artists also depicted birds. In historical times, the mating and migration behavior of geese, ducks and sea mammals served as cues for seasonal changes to Northwest Coast Native Americans and Inuit. The use of these animals as temporal cues by contemporary hunter-gatherers suggests that their representation served as external storage of cues for seasonal changes. D'Errico's (1994) detailed analysis of a scene depicting three birds identified as great auks (Pinguinus impennis) at the Cosquer cave (Bouches-du-Rhône, France) supports this interpretation (Fig. 3). The pigments of this rock painting were directly dated to about 26,400 BP (Clottes et al., 1992). These large, flightless, now-extinct birds seasonally flocked to form large breeding colonies on offshore islands. This behavior was restricted to early summer, when mating occurred, eggs were hatched and chicks raised.

Fig. 3: Scene depicting three auks at the Cosquer cave. This scene shows gregarious behavior, which was seasonally restricted to early summer.
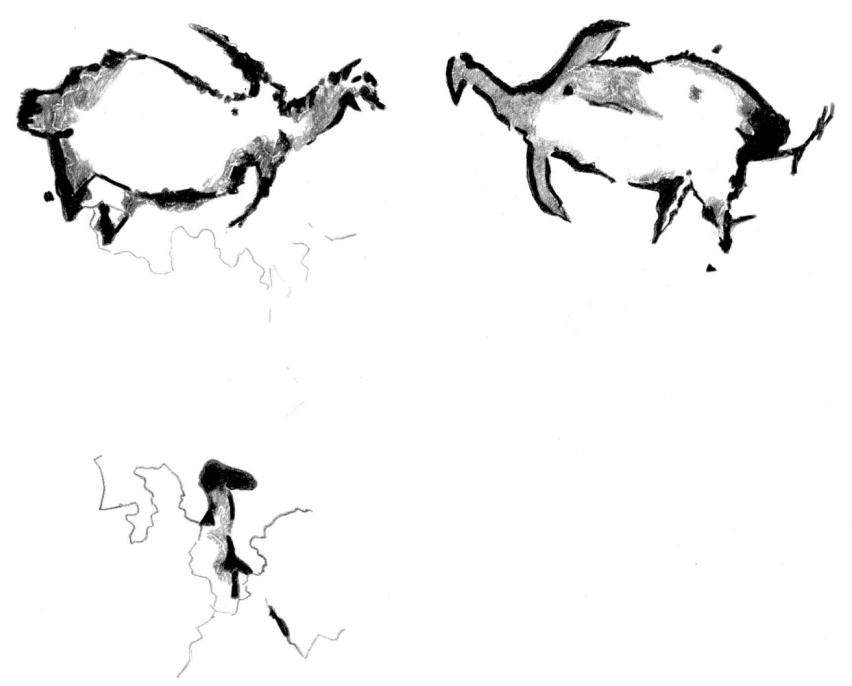

The scene shows three individuals, two facing each other with wings outspread, and a third, lying down with wings folded. As in all Alcidae, the great auk's wings were useless 
for flight; they were only used during swimming or in combat for mates, when they were vigorously flapped. D'Errico (1994) interprets the opposing pair as males in combat, the third bird as a female they are disputing. A less gladiatorial interpretation (McDonald 1994 ) is that the upper individuals are foraging underwater (swimming is indicated by their outspread wings), and that the lower individual represents their single chick (auks laid only one egg per season and both parents raised the offspring). Whichever interpretation one favors, it is important to point out that the scene shows gregarious behavior in auks which was seasonally restricted to early summer. The conspicuousness of large breeding colonies on nearby islands may have been useful for prehistoric huntergatherers as a material anchor for seasonal events related to the beginning of summer. Rock paintings depicting this behavior may thus have served as artificial memory systems to recall and communicate its significance as a temporal marker. A rock engraving with a comparable function has been identified in the Elvina track engraving site at Ku-ring-gai Chase National Park, $20 \mathrm{~km}$ north of Sydney. This engraving of a large bird represents the "Emu in the Sky," a common Australian aboriginal term for the cloud of interstellar dust close to the Southern Cross. Interestingly, the engraved bird only aligns with that constellation during early autumn, at just the time of year when reallife emus are laying their eggs (Norris \& Hamacher, 2009). Great auks went extinct around 1844 . Because they usually returned to the same location to breed, they easily fell prey to sailors and fishermen who captured them in large quantities during their breeding season for meat, fat and feathers. Auk bones are also present in numerous Upper Paleolithic Mediterranean sites, indicating that prehistoric hunters also regularly included these birds in their diet.

Contemporary and historical small-scale societies often rely on star clusters as an aid to keep track of time. The Iroquois and the Algonquians (both Native American peoples) used the Pleiades to time the cultivation of their staple food, maize, which was grown at the northern fringes of the range in which it is possible to cultivate it. The appearance of the Pleiades coincides with the then limits of the frost-free periods of sowing and reaping (Ceci, 1978). The pervasive role of the Pleiades in folk astronomy (in places as widespread as East-Africa, Melanesia, North America and Siberia) can be explained by their visibility: to the naked eye they form the most visible cluster of stars in the night sky with a marked cyclicity. The archeoastronomer Michael Rappenglück (2001; 2004) has recognized the Pleiades on paintings of the caves of La-Tête-du-Lion (Ardèche, France, 21,000 BP) and Lascaux, indicating that Paleolithic people used this easily recognizable star cluster, probably also for calendrical reasons.

\subsection{Improved foraging success}

In what ways does the use of epistemic artifacts extend human cognition? Although cognition itself does not fossilize, we can infer changes in cognition through changes in behavior which leave their marks in the fossil and archeological records. Many archeologists (e.g., Klein, 2001) observe a discontinuity in subsistence patterns and other forms of behavior during the Late Pleistocene. In the archeological record, there is evidence for behavioral innovations in diverse domains during this period. Technological innovations included the invention of highly specialized weaponry, such as harpoons and spear throwers, and improvements in lithic technology, such as the invention of microliths, which had a much higher ratio of cutting edge versus tool weight compared to earlier stone technology (Leroi-Gourhan, 1993, 136). In the European archeological record, there is also clear evidence that Middle Paleolithic (MP) hominids hunted and gathered less efficiently than those of the Upper Paleolithic (UP). Improvements in technology can partly account for this increased efficiency. However, there is also 
evidence that the increased effectiveness in foraging was due to a better recognition of cyclical events. Take the transition from MP to UP in the southern Russian plains. In marked contrast to the earlier (MP) occupations, later (UP) sites show fewer species of prey and less variability in the concentration of fossil bones across seasons. This is taken as evidence for higher selectivity in the choice of prey and time of occupation, indicating specialized hunting and seasonal occupation of sites tuned to animal migrations (Soffer, 1989).

The Aurignacian site of Vogelherd, (Lone Valley, Germany), dated to 33,000$30,000 \mathrm{BP}$, provides a good illustration of seasonal occupation. The main sources of food for these Pleistocene hunters were reindeer and horses. Both species were highly seasonal in birthing and mating, and they migrated seasonally through the Lone Valley, using the natural routes that dissected it. As present-day wild horses and reindeer are quite predictable in their migration patterns (not following exactly the same route, but approximately so), it would have been advantageous for the Aurignacian inhabitants of Southwestern Germany to be able to predict these migrations. An analysis of the tooth eruption patterns of reindeer remains at Vogelherd indicates that these animals were primarily hunted during the fall migration. The horse bones, likewise, indicate that horses were hunted when they migrated in large family groups consisting of mares and maturing foals during late summer and fall. Indeed, evidence for occupation of Vogelherd at other times of the year is lacking (Niven, 2007, p. 377). Niven (2007) infers from these patterns that Vogelherd was not occupied all year round, but seasonally during the annual fall migrations of large herbivores - the density of the archaeological material moreover suggests that it was used multiple times. Given that hunter-gatherers inhabit extensive ranges (between 314 to $2500 \mathrm{~km}^{2}$ (Mandryk, 1993), probably closer to the high value in the Ice Age Aurignacian), and taking into account the presence of exotic lithic material (i.e., stone tools made from cores that were found over one hundred kilometers away), this seasonal occupation suggests that the inhabitants of Vogelherd could anticipate these migration events. Unlike reindeer, whose migratory behavior is regulated by the secretion of hormones like melatonin as a function of exposure to daylight hours, humans do not have physiological adaptations to time their migrations. A plausible explanation of their accurate, long distance travels to Vogelherd is their access to calendrical devices.

The African archeological record shows a similar pattern: Later Stone Age (LSA) sites indicate an increased foraging efficiency compared to Middle Stone Age (MSA) locales. These improvements are not caused by changes in climate or prey availability as the South African Last Interglacial and the Present Interglacial are climatologically very similar. Yet LSA sites from the Present Interglacial show improved foraging efficiency, such as an increase in bird and fish bones compared to MSA sites (Klein, 2001). The failure of earlier humans to recognize or record cyclicity in their environment could explain this difference. Material culture allowed the recording of cyclical patterns, enabling hunter-gatherers to time their visits to sites according to patterns in animal migration and plant growth. The capture of Cape fur seals (Arctocephalus pusillus) in southwestern African coastal sites presents a pertinent case study (Klein, Cruz-Uribe, \& Skinner, 1999). Fur seals breed on offshore islands, the majority of births occurring during late November and early December. About nine months later, adult seals force their young from the rocks into sea. Large numbers of these young seals wash ashore, exhausted or dead - an ideal time for mobile hunter-gatherers to visit these sites. Like in the European archeological record, only humans from Later Stone Age sites appear to recognize this cyclical pattern: fossil remains from seals in LSA sites indeed mostly represent individuals of about nine months old, implying that these people timed their visits to the coast to fall within the August-October peak in juvenile seal availability. In 
contrast, Middle Stone Age sites do not show such a fixed pattern. The bones of seals recovered from these sites are commonly older, ranging from sub-adults to adults, not showing any cyclicity at all, a pattern remarkably similar to that found in dens of fossil hyenas.

Recognizing cyclicity not only had an impact on hunting success, but also resulted in a substantial broadening of the human diet. Fish bones are notably absent in the MP archeological record-exceptions include the opportunistic and occasional exploitation of marine shellfish by Neanderthals at Mediterranean coastal sites. In contrast, numerous archeological sites indicate that coastal UP people relied heavily on fish for their diet. These sites show patterns of seasonal and specialized fish exploitation. The relative proportion of aquatic resources in the diet of prehistoric foragers can also be directly inferred through analysis of the stable isotope values of carbon $\left(\delta^{13} C\right)$ and nitrogen $\left(\delta^{15} \mathrm{~N}\right)$ in their bone collagen. These data provide direct information about average dietary protein intake by prehistoric consumers over a period of ten years prior to their death. Richards, Pettitt, Stiner, and Trinkaus (2001) found that fish only became incorporated in European diets by the middle UP (about 30,000 BP). Prior to this time, the principal sources of animal protein were large herbivores. The trend of including fish in the diet coincides with elaborations in material culture, such as lavish burials, personal ornaments, portable art and notched artifacts. Likewise, at the African LSA site of Ishango, Congo, along the Upper Semliki River, dense concentrations of fish remains, together with hundreds of barbed points used to spear the fish, dated at about 25,000 BP, have been recovered (Stewart, 1994). More than 30\% of these remains belong to the genus Barbus, a large minnow-like fish. Their size range represents primarily mature individuals, probably caught on their spawning migration, the only time of the year when fish are truly fat. This implies that the fishers at Ishango timed their capture to the rainy season, when large quantities of Barbus congregate in river mouths on their yearly spawning migration. The repeated rainy season occupations at Ishango indicate the predictability of these. Interestingly, two incised bones dating to the same period have been recovered at Ishango. The spatial distribution of their notches (Fig. 4) almost certainly indicates that they are artificial memory systems. One reason why MSA people neglected such a stable and abundant food source may be that the systematic exploitation of fish requires recognizing cyclical patterns of spawning and migration. In historical times, the Northwest Coast Native Americans planned and prepared for the capture of salmon months in advance.

Fig. 4: Incised bone from Ishango, Congo, dated to 25,000-20,000 BP. Photograph by second author, with permission of the Museum of Natural Sciences, Brussels, Belgium. Marshack (1991) interpreted this object as a lunar calendar, each row representing 60 days (approximately two observational lunar months).

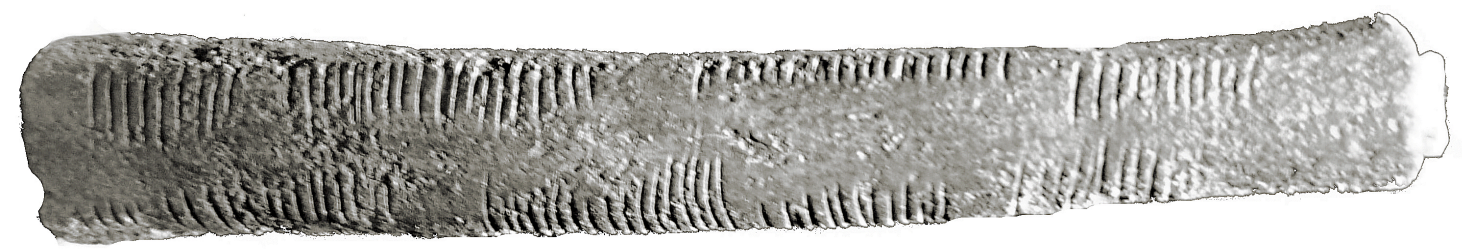

Recognizing cyclicity has an impact on many aspects of human life. Traditional human diets in which plants are rare, such as those of the Inuit, show a strong 
relationship between physiological stress, group size and dietary fat. The human body's ability to metabolize energy from protein is limited; a critical ratio of protein to fat must be maintained to prevent starvation. As mentioned earlier, the animals that Late Pleistocene humans hunted - as indicated by bone collagen analysis and archeological remains-provided mostly lean meat, which contains mainly protein and little fat. Hunting animals with high fat content requires the detection of cyclical patterns, as animals only accumulate fat during specific phases of their life-cycle: fish are only fat while returning upstream to spawn, terrestrial herbivores only accumulate fat prior to migration, mating or giving birth. A comparative study of traditional Inuit diets with differing protein to fat ratios (Cachel, 1997) indicates that groups with high protein/low fat diets are smaller and have less complex social structures (with little social stratification). Their members suffer more physiological stress, such as bone fractures. Applying these observations to Late Pleistocene Europe, it becomes apparent that Neanderthals (associated with MP industries) consumed less fat than anatomically modern humans (associated with UP assemblages). Although Neanderthals were highly successful hunters, focusing on prime-age individuals (Steele, 2003), they had relatively low population densities and suffered many traumatic injuries-Berger and Trinkaus (1995) aptly compare them to rodeo veterans. Their burial patterns do not suggest social stratification. In marked contrast, the population density of anatomically modern humans, as indicated by site density, was higher, and their fossil remains show less traumatic injuries. Their burial patterns hint at more complex social structures as is indicated amongst others by grave gifts of exotic origin at the Saint-Germain-la-Rivière burial dated at about 15,600 BP (Vanhaeren \& d'Errico, 2005). Moreover, detailed study of the processing of carcasses of reindeer and other large mammals by anatomically modern humans (e.g., Niven, 2007) indicates that modern humans invested considerable time and effort in exploiting fat-rich parts of those carcasses (such as the extensive processing of lower hindlimbs). The failure of earlier humans to recognize cyclicity in their environment could explain these behavioral differences.

\section{Concluding remarks}

In this paper, we examined anthropological and archeological evidence for the use of the external environment as an extension of mental time travel. The anthropological case studies indicate that humans use a variety of naturally occurring objects and especially designed artifacts for this purpose. Because only a tiny fraction of material culture survives in the archeological record (i.e., only objects that are in a suitable context, and that are made of hard materials, such as stone and bone), the Late Pleistocene artifacts we discussed are probably only a fraction of the calendrical systems that were being used. Nevertheless, when such artifacts begin to consistently appear in the archeological record, we see an improvement in foraging success, especially in the exploitation of cyclical resources. The invention of calendrical systems can be seen in the broader context of technological and behavioral innovations that occurred during the MP to UP transition.

The fragmentary nature of the archaeological record makes it at present difficult to model the claims put forward in this paper. However, recent computational models that have examined the evolution of communication (e.g., di Paolo, 1997) and the role of population dynamics in the emergence of culturally modern behavior (e.g., Powell et al. 2009) could be adapted to model the role of external media in human behavior during the Upper Paleolithic. Current analytic models (e.g., Henrich, 2004) examine relationships between population size and technological and behavioral innovation. However, to date 
such models do not take into account the role of externally stored knowledge in cultural evolution. As we have seen, the ethnographic and archaeological record suggest that storing knowledge outside of the brain increases the reliability of representations and protects them against various memory biases. Therefore, future computational and analytic models should incorporate this reliance on externally stored knowledge as a factor in the transmission of information and skills.

\section{Acknowledgements}

Elements of this paper were presented at the Second European Cognitive Science Conference in Delphi, Greece (23-27 May, 2007). This research is supported by grant COM07/PWM/001 from Ghent University and the Research Foundation Flanders. We thank two anonymous reviewers and Ezequiel Di Paolo for their helpful comments.

\section{References}

Addis, D., Wong, A. \& Schacter, D. (2007). Remembering the past and imagining the future: Common and distinct neural substrates during event construction and elaboration. Neuropsychologia, 45, 1363-1377.

Atance, C. \& O’Neill, D. (2001). Episodic future thinking. Trends in Cognitive Science, $5,533-539$.

Bassi, M. (1988). On the Borana calendrical system: A preliminary field report. Current Anthropology, 29, 619-624.

Bateson, M. (2003). Interval timing and optimal foraging. In W. Meck (Ed.), Functional and Neural Mechanisms of Interval Timing (pp. 113-141). Broca Raton: CRC Press.

Baxter, M. (2001). Methodological issues in the study of assemblage diversity. American Antiquity, 66, 715-725.

Berger, T., \& Trinkaus, E. (1995). Patterns of trauma among the Neandertals. Journal of Archaeological Science, 22, 841-852.

Breuer, T., Ndoundou-Hockembal, M. \& Fishlock, V. (2005). First observation of tool use in wild gorillas. PLoS Biology, 3, e380.S.

Cachel, S. (1997). Dietary shifts and the European Upper Palaeolithic transition. Current Anthropology, 38, 579-603.

Caspari, R., \& Lee, S.-H. (2004). Older age becomes common late in human evolution. Proceedings of the National Academy of Sciences of the USA, 101, 10895-10900.

Ceci, L. (1978). Watchers of the Pleiades: Ethnoastronomy among native cultivators in northeastern North America. Ethnohistory, 25, 301-317. 
Chandrasekharan, S., \& Stewart, T.C. (2007). The origin of epistemic structures and proto-representations. Adaptive Behavior, 15, 329-353.

Clark, A., \& Chalmers, D. (1998). The extended mind. Analysis, 58, 7-19.

Clarke, P.A. (2009). Australian aboriginal ethnometereology and seasonal calendars. History and Anthropology, 20, 79-106.

Clayton, N., \& Dickinson, A. (1998). Episodic-like memory during cache recovery by scrub jays. Nature, 395, 272-274.

Clottes, J., Courtin, J., Valladas, H., Cachier, H., Mercier, N. \& Arnold, M. (1992). La grotte Cosquer datée. Bulletin de la Société Préhistorique française, 89, 230-234.

Delluc, B., \& Delluc, C.R. (2006). Art paléolithique, saisons et climats. Comptes Rendus Palevol, 5, 203-211.

d'Errico, F. (1994). Birds of Cosquer cave. The great auk (Pinguinus impennis) and its significance during the Upper Palaeolithic. Rock Art Research, 11, 45-57.

d'Errico, F. (1998). Palaeolithic origins of artificial memory systems: An evolutionary perspective. In C. Renfrew \& C. Scarre (Eds.), Cognition and material culture: The Archaeology of symbolic storage (pp. 19-50). Cambridge: McDonald Institute for Archaeological Research.

Di Paolo, E.A. (1997). An investigation into the evolution of communication. Adaptive Behavior, 6, 285-324.

Ghezzi, I., \& Ruggles, C. (2007). Chankillo: A 2300-year-old solar observatory in coastal Peru. Science, 315, 1239-1243.

Gilbert, D.T., Gill, M.J., \& Wilson, T.D. (2002). The future is now: Temporal correction in affective forecasting. Organizational Behavior and Human Decision Processes, 88, 430-444.

Hassabis, D., Kumaran, D., Vann, S., \& Maguire, E. (2007). Patients with hippocampal amnesia cannot imagine new experiences. Proceedings of the National Academy of Sciences USA, 104, 1726-1731.

Henrich, J. (2004). Demography and cultural evolution: How adaptive cultural processes can produce maladaptive losses-The Tasmanian case. American Antiquity, 69, 197-214.

Hutchins, E. (1995). Cognition in the wild. Cambridge, MA: MIT Press.

Jègues-Wolkiewiez, C. (2005). Aux racines de l'astronomie, ou l'ordre caché d'une œuvre paléolithique. Antiquités Nationales, 37, 43-62.

Kirsh, D. (1996). Adapting the environment instead of oneself. Adaptive Behavior, 4, 415-452. 
Kirsh, D., \& Maglio, P. (1994). On distinguishing epistemic from pragmatic action. Cognitive Science, 18, 513-549.

Klein, R. (2001). Southern Africa and modern human origins. Journal of Anthropological Research, 57, 1-16.

Klein, R., Cruz-Uribe, K., \&. Skinner, J. (1999). Fur seal bones reveal variability in prehistoric human seasonal movements on the southwest African coast. Archaeozoologia, $10,181-188$.

Kummer, H. (1995). Causal knowledge in animals. In D. Sperber, D. Premack \& A. Premack (Eds.), Causal Cognition. A Multidisciplinary Debate (pp. 26-36). Oxford: Clarendon Press.

Leroi-Gourhan, A. (1993). Gesture and speech. Cambridge, MA: MIT Press.

Loftus, E. (2003). Make-believe memories. American Psychologist, 58, 867-873.

Mandryk, C.A.S. (1993). Hunter-gatherer social costs and the nonviability of submarginal environments. Journal of Anthropological Research, 49, 39-71.

Marsh, E., \& Tversky, B. (2004). Spinning the stories of our lives. Applied Cognitive Psychology, 18, 491-503.

Marshack, A. (1972). Cognitive aspects of Upper Paleolithic engraving. Current Anthropology, 13, 445-461.

Marshack, A. (1991). The Taï plaque and calendrical notation in the Upper Palaeolithic. Cambridge Archaeological Journal, 1, 25-61.

McDonald, J. (1994). Identifying great auks and other birds in Palaeolithic art of western Europe. Antiquity, 68, 850-858.

Mithen, S. (1988). Looking and learning: Upper Palaeolithic art and information gathering. World Archaeology, 19, 297-327.

Mithen, S. (2000). Mind, brain and material culture: An archaeological perspective. In P. Carruthers \& A. Chamberlain (Eds.), Evolution and the human mind. Modularity, language and meta-cognition (pp. 207-217). Cambridge: Cambridge University Press.

Mondragón, C. (2004). Of winds, worms and mana: The traditional calendar of the Torres Islands, Vanuatu. Oceania, 74, 289-308.

Morewedge, C.K., Gilbert, D.T., \& Wilson, T.D. (2005). The least likely of times: How remembering the past biases forecasts of the future. Psychological Science, 16, 626-630.

Niven, L. (2007). From carcass to cave: Large mammal exploitation during the Aurignacian at Vogelherd, Germany. Journal of Human Evolution, 53, 362-382. 
Nooter Roberts, M. \& Roberts, A. (1996). Memory: Luba art and the making of history. New York: Museum for African Art.

Norris, R.P., \& Hamacher, D.W. (2009). The astronomy of aboriginal Australia. In D. Valls-Gabaud \& A. Boksenberg (Eds.), The rôle of astronomy in society and culture (pp. 10-17). Paris: International Astronomical Union.

Perner, J., \& Ruffman, T. (1995). Episodic memory and autonoetic consciousness: Developmental evidence and a theory of childhood amnesia. Journal of Experimental Child Psychology, 59, 516-546.

Powell, A., Shennan, S., \& Thomas, M. (2009). Late Pleistocene demography and the appearance of modern human behavior. Science, 324, 1298-1301.

Raby, C.R., Alexis, D.M., Dickinson, A., \& Clayton, N. (2007). Planning for the future by western scrub-jays. Nature, 445, 919-921.

Radcliffe-Brown, A. (1922). The Andaman islanders. New York: Free Press of Glencoe.

Rappenglück, M. (2001). Palaeolithic timekeepers looking at the golden gate of the ecliptic: The lunar cycle and the Pleiades in the cave of La-Tête-du-Lion (Ardèche, France) - 21,000 BP. Earth, Moon and Planets, 85/86, 391-404.

Rappenglück, M. (2004). A Palaeolithic planetarium underground-The cave of Lascaux. Migration \& Diffusion, 5, 93-119.

Richards, M., Pettitt, P., Stiner, M. \& Trinkaus E. (2001). Stable isotope evidence for increasing dietary breadth in the European mid Upper Paleolithic. Proceedings of the National Academy of Sciences USA, 98, 6528-6532.

Roberts, R.G., Jones, R., \& Smith, M.A. (1990). Thermoluminescence dating of a 50,000-year-old human occupation site in northern Australia. Nature, 345, 153-156.

Sansom, B. (2006). The brief reach of history and the limitation of recall in traditional aboriginal societies and cultures. Oceania, 76, 150-172.

Sharifian, F. (2003). On cultural conceptualizations. Journal of Cognition and Culture, 3, 187-207.

Shine, R., \& Brown G.P. (2008). Adapting to the unpredictable: Reproductive biology of vertebrates in the Australian wet-dry tropics. Philosophical Transactions of the Royal Society B, 363, 363-373.

Soffer, O. (1989). The Middle to Upper Palaeolithic transition on the Russian plain. In P. Mellars \& C. Stringer (Eds.), The human revolution. Behavioural and biological perspectives in the origins of modern humans (pp. 714-742). Edinburgh: Edinburgh University Press.

Steele, T. (2003). Using mortality profiles to infer behavior in the fossil record. Journal of Mammalogy, 84, 418-430. 
Stevens, J.R., Rosati, A.G., Ross, K.R., \& Hauser, M.D. (2005). Will travel for food: Spatial discounting in two New World monkeys. Current Biology, 15, 1855-1860.

Stewart, K. (1994). Early hominid utilisation of fish resources and implications for seasonality and behaviour. Journal of Human Evolution, 27, 229-245.

Suddendorf, T., Addis, D.R., \& Corballis, M.C. (2009). Mental time travel and the shaping of the human mind. Philosophical Transactions of the Royal Society B, 364, $1317-1324$

Suddendorf, T. \& Corballis, M.C. (1997). Mental time travel and the evolution of the human mind. Genetic, Social and General Psychology Monographs, 123, 133-167.

Thompson, C., Barresi, J. \& Moore, C. (1997). The development of future-oriented prudence and altruism in preschoolers. Cognitive Development, 12, 199-212.

Thornton, R. (2003). A report of a new Mandan calendric chart. Ethnohistory, 50, 697-705.

Tulving, E. (2002). Episodic memory: From mind to brain. Annual Review of Psychology, 53, 1-25.

Tversky, B. \& Marsh, E. (2000). Biased retellings of events yield biased memories. Cognitive Psychology, 40, 1-38.

Vanhaeren, M. \& d'Errico, F. (2005). Grave goods from the Saint-Germain-la-Rivière burial: Evidence for social inequality in the Upper Palaeolithic. Journal of Anthropological Archaeology, 24, 117-134. 